\title{
Formation of Mercury(II)-Glutathione Conjugates Examined Using High Mass Accuracy Mass Spectrometry
}

\author{
Zachary Fine ${ }^{1}$, Troy D. Wood ${ }^{2 *}$ \\ ${ }^{1}$ Department of Chemical and Biological Engineering, University at Buffalo, State University of New York, Buffalo, USA \\ ${ }^{2}$ Department of Chemistry, University at Buffalo, State University of New York, Buffalo, USA \\ Email: "twood@buffalo.edu
}

Received October 12, 2013; revised November 9, 2013; accepted December 10, 2013

Copyright (C) 2013 Zachary Fine, Troy D. Wood. This is an open access article distributed under the Creative Commons Attribution License, which permits unrestricted use, distribution, and reproduction in any medium, provided the original work is properly cited. In accordance of the Creative Commons Attribution License all Copyrights (C) 2013 are reserved for SCIRP and the owner of the intellectual property Zachary Fine, Troy D. Wood. All Copyright (C) 2013 are guarded by law and by SCIRP as a guardian.

\begin{abstract}
Maternal exposure to $\mathrm{Hg}(\mathrm{II})$ during pregnancy has been identified as a potential causal factor in the development of severe neurobehavioral disorders. Children with autism have been identified with lower reduced glutathione (GSH)/oxidized glutathione (GSSG) ratios, and GSH is known to strongly bind $\mathrm{Hg}(\mathrm{II})$. In order to gain insight into the mechanism by which GSH binds $\mathrm{Hg}(\mathrm{II})$, high resolution mass spectrometry coupled with tandem mass spectrometry was utilized to examine the conjugation process. While the $1: 1 \mathrm{Hg}(\mathrm{II})$ :GSH conjugate is not formed immediately upon mixing aqueous solutions of $\mathrm{Hg}(\mathrm{II})$ and $\mathrm{GSH}$, two species containing $\mathrm{Hg}(\mathrm{II})$ are observed: the 1:2 $\mathrm{Hg}(\mathrm{II}): \mathrm{GSH}$ conjugate, $\left[(\mathrm{GS})_{2} \mathrm{Hg}+\mathrm{H}^{+}\right]$, and a second $\mathrm{Hg}(\mathrm{II})$-containing species around $\mathrm{m} / \mathrm{z} 544$. Interestingly, this species at $\mathrm{m} / z 544$ decreases in time while the presence of the 1:1 $\mathrm{Hg}(\mathrm{II})$ :GSH conjugate increases, suggesting that $\mathrm{m} / z$ 544 is an intermediate in the formation of the 1:1 conjugate. Experiments using the high mass accuracy capability of Fourier transform ion cyclotron resonance (FT-ICR) mass spectrometry coupled to an electrospray ionization source indicate that the intermediate species is $[\mathrm{GSH}+\mathrm{HgCl}]^{+}$, and not the $1: 1$ conjugate $\left[\mathrm{Hg}(\mathrm{GSH})-\mathrm{H}+2 \mathrm{H}_{2} \mathrm{O}\right]^{+}$postulated in previous literature. Further confirmation of [GSH $+\mathrm{HgCl}]^{+}$is supported by collision of induced dissociation experiments, which show neutral loss of $\mathrm{HCl}$ from the intermediate and loss of the $\mathrm{N}$ - and $\mathrm{C}$-terminal amino acids, indicating binding of $\mathrm{Hg}(\mathrm{II})$ at the Cys residue.
\end{abstract}

Keywords: Glutathione; Mercury; FT-ICR; Mass Spectrometry; Tandem Mass Spectrometry

\section{Introduction}

Glutathione (GSH, $\gamma$ Glu-Cys-Gly) is a tripeptide with a reactive thiol group found in relatively high intracellular concentrations, and it is the primary regulator of cellular redox homeostasis paired with its disulfide (GSSG) [1,2]. Some heavy metals such as $\mathrm{Hg}(\mathrm{II})$ are toxic to cells because of their ability to deplete GSH [3]. The binding constant of $\mathrm{Hg}(\mathrm{II})$ to GSH is very large as measured by polarographic [4] and nuclear magnetic resonance [5] methods. Zalups has expertly reviewed the role of thiolcontaining proteins, including GSH, and their interactions with $\mathrm{Hg}(\mathrm{II})$ in uptake, accumulation, transport, and toxicity [6].

Electrospray ionization mass spectrometry (ESI-MS) has been used previously to examine the conjugation of Hg(II) with GSH [7-11]. The studies of Rubino et al. ${ }^{*}$ Corresponding author. provided insight into the stoichiometry of binding between $\mathrm{Hg}$ (II) and GSH, with particular attention on the dissociation behavior of the conjugates under collisionally induced dissociation (CID) conditions by tandem mass spectrometry (MS/MS) [9,11]. Interestingly, it was found that the $1: 1 \mathrm{Hg}(\mathrm{II})$ : GSH conjugates require significantly higher collisional activation energy than the $1: 2 \mathrm{Hg}(\mathrm{II}): \mathrm{GSH}$ or the $1: 1 \mathrm{Hg}(\mathrm{II})$ :GSSG conjugates, suggesting strong coordination of $\mathrm{Hg}(\mathrm{II})$ at the carboxy terminus of GSH [9]. Burford et al. examined $\mathrm{Hg}(\mathrm{II})$ conjugation to GSH in both positive ion and negative ion ESI-MS, and also found the existence of $1: 1$ and 1:2 $\mathrm{Hg}(\mathrm{II})$ :GSH conjugates [10]. Burford et al.'s results were replicated by positive ion ESI-MS and it was found that $\mathrm{Hg}$ (II):GSH conjugates spiked into plant extracts could be recovered and detected [8]. Of particular note was the publication of detailed isotopic insets, which proved that 
$\mathrm{Hg}$ (II) was indeed conjugated to GSH [8]. A mercuryglutathione conjugate with 1:3 Hg(II):GSH stoichiometry has been shown in negative ion mode ESI-MS [7].

Here, we report on the conjugation between $\mathrm{Hg}$ (II) and GSH using high resolution mass spectrometry. Our motivation for this investigation stems from three items. First, lower GSH:GSSG ratios in the plasma of children with autism have been found, which have been related to oxidative stress [12]. Second, as detailed thoroughly in reviews $[13,14]$, there is an extensive evidence that exposure to mercury leads to neurological conditions. Third, all the previous ESI-MS reports were done on relatively low-resolution mass spectrometers, and we felt that an investigation using high resolution mass spectrometry would be useful to validate earlier studies and resolve existing ambiguities in interpretation of the ESI mass spectra from $\mathrm{Hg}(\mathrm{II})$ :GSH conjugates. ESI coupled to Fourier transform ion cyclotron resonance mass spectrometry (ESI-FTICR) is used in the current investigation. The high resolution mass spectrometry data provide a keen insight into the mechanism by which $\mathrm{Hg}(\mathrm{II}): \mathrm{GSH}$ conjugates form.

\section{Experimental}

All high resolution mass measurements were acquired using a Bruker Daltonics (Billerica, MA) 12 tesla SolariX FT-ICR mass spectrometer equipped with an ESI source. Mercuric nitrate (J. T. Baker, Phillipsburg, NJ) and reduced glutathione (Sigma-Aldrich, St. Louis, MO) were prepared as separate aqueous solutions, each at 10 $\mu \mathrm{g} / \mathrm{mL}$. These were then mixed in a 1:1 volume:volume ratio and then loaded into a syringe for infusion into the ESI source. ESI was performed at $5.4 \mathrm{kV}$ using $\mathrm{N}_{2}$ nebulizer gas $(2.9 \mathrm{~L} / \mathrm{min})$ by infusing the sample mixture via syringe pump at $3.0 \mu \mathrm{L} / \mathrm{min}$ and applying $\mathrm{N}_{2}$ drying gas $\left(2.8 \mathrm{~L} / \mathrm{min}, 200^{\circ} \mathrm{C}\right)$ to desolvate the droplets. Ions were accumulated in the external quadrupole for $100 \mathrm{~ms}$ before transfer through the external ion optics to the FT-ICR trap. Ions were trapped in an Infinity cell (front trap plate $0.6 \mathrm{~V}$, back trap plate $0.8 \mathrm{~V}$ ) [15] operating at $\sim 1 \times 10^{-9}$ mbar, and excited and detected in broadband mode as positive ions over $\mathrm{m} / \mathrm{z} 98.3-3000$ using $2 \mathrm{MB}$ time domain data sets; the data was zero-filled once and displayed in the magnitude mode. The resulting FT-ICR mass spectra are from the summation of 100 individual scans. Collision induced dissociation (CID) experiments were performed by isolation of the isotopic cluster in the mass-selective quadrupole and dissociation in the collision cell with argon gas $\left(\sim 1 \times 10^{-3}\right.$ mbar $)$. All isotope distributions were simulated using the proposed ionic formulas using the IsotopePattern utility in Bruker Daltonics' Compass software package.

\section{Results and Discussion}

Upon mixing $10 \mu \mathrm{g} / \mathrm{mL}$ aqueous solutions of mercuric nitrate and GSH, ESI-FTICR mass spectra were collected immediately and the resulting data is shown in Figure 1(a). One of the primary analytical advantages of FTICR is its ability to measure ionic masses with unparalleled accuracy [16]. Accurate mass measurements confirm the presence of $(\mathrm{M}+\mathrm{H})^{+}$for both reduced glutathione (308.09317 $\mathrm{Da},+2.1 \mathrm{mDa}$ error) and oxidized glutathione (613.1633 $\mathrm{Da},+4.1 \mathrm{mDa}$ error). In addition, two peaks due to dioctyl phthalate, a common plasticizer, are observed, which include $(\mathrm{M}+\mathrm{H})^{+}$at 391.2870 Da $(+2.7 \mathrm{mDa}$ error $)$ and $(\mathrm{M}+\mathrm{Na})^{+}$at $413.2690 \mathrm{Da}(+2.8$ $\mathrm{mDa}$ error) which serve as internal mass calibrants. As shown in the inset of Figure 1(a), a very weak peak (less than $1 \%$ relative abundance) due to an isotopic cluster with its most abundant peak at $m / z 815.1349$ is attributed to $\left[(\mathrm{GS})_{2} \mathrm{Hg}+\mathrm{H}^{+}\right](+5.2 \mathrm{mDa})$; this species has been observed in previous reports of $\mathrm{Hg}$ (II) conjugated to GSH [8-11]. A 1:1 Hg(II):GSH conjugate is not observed immediately after mixing, but a curious isotopic cluster centered around $\mathrm{m} / \mathrm{z} 544$ having an isotopic pattern consistent with a single $\mathrm{Hg}$ (II) is observed. Only once has this species been reported in positive ion ESI mass spectra, and that was collected at low resolution; hence, the identity of the species remained ambiguous, although it was speculated that the species responsible "might be a Hg-GS cluster with two water molecules associated with it" [8]. However, as discussed below, high mass accuracy and MS/MS reveal another composition involving $\mathrm{Hg}(\mathrm{II})$. Interestingly, with time the $1: 1 \mathrm{Hg}(\mathrm{II})$ :GSH conjugate appears, and after four days of incubation at room temperature, it becomes by far the dominant $\mathrm{Hg}(\mathrm{II})$-containing species in the ESI-FTICR mass spectrum (Figure 1(b)); $\left[(\mathrm{GS})_{2} \mathrm{Hg}+\mathrm{H}^{+}\right]$is still present, but remains weak.

Intrigued by the fact that the species containing $\mathrm{Hg}$ (II) around $\mathrm{m} / \mathrm{z} 544$ decreases with time while the $1: 1$ $\mathrm{Hg}(\mathrm{II}): \mathrm{GSH}$ conjugate around $\mathrm{m} / \mathrm{z} 508$ increases with time, we compared the high mass accuracy for the $\mathrm{m} / \mathrm{z}$ 544 conjugate and its isotopic distribution against that previously predicted [8]. Figure 2(a) represents an inset of the isotopic distribution measured around $m / z 544$ by ESI-FTICR, and bears a striking similarity to the isotopic distribution reported for this ion by Krupp et al. in Figure $2 \mathrm{~d}$ of their paper [8], suggesting these are in fact due to the same ionic species. However, this experimentally-derived result does not match well with the theoretically-predicted isotopic distribution for the postulated $\left[\mathrm{Hg}(\mathrm{GSH})-\mathrm{H}+2 \mathrm{H}_{2} \mathrm{O}\right]^{+}$(Figure 2(b)) [8]. Accurate mass measurement of the nominal $\mathrm{m} / \mathrm{z} 544$ peak by ESIFTICR is $544.0263 \mathrm{Da}$, which further indicates $[\mathrm{Hg}(\mathrm{GSH})$ $\left.-\mathrm{H}+2 \mathrm{H}_{2} \mathrm{O}\right]^{+}$cannot be the identity of this ionic species. However, this accurate mass measurement is in close 


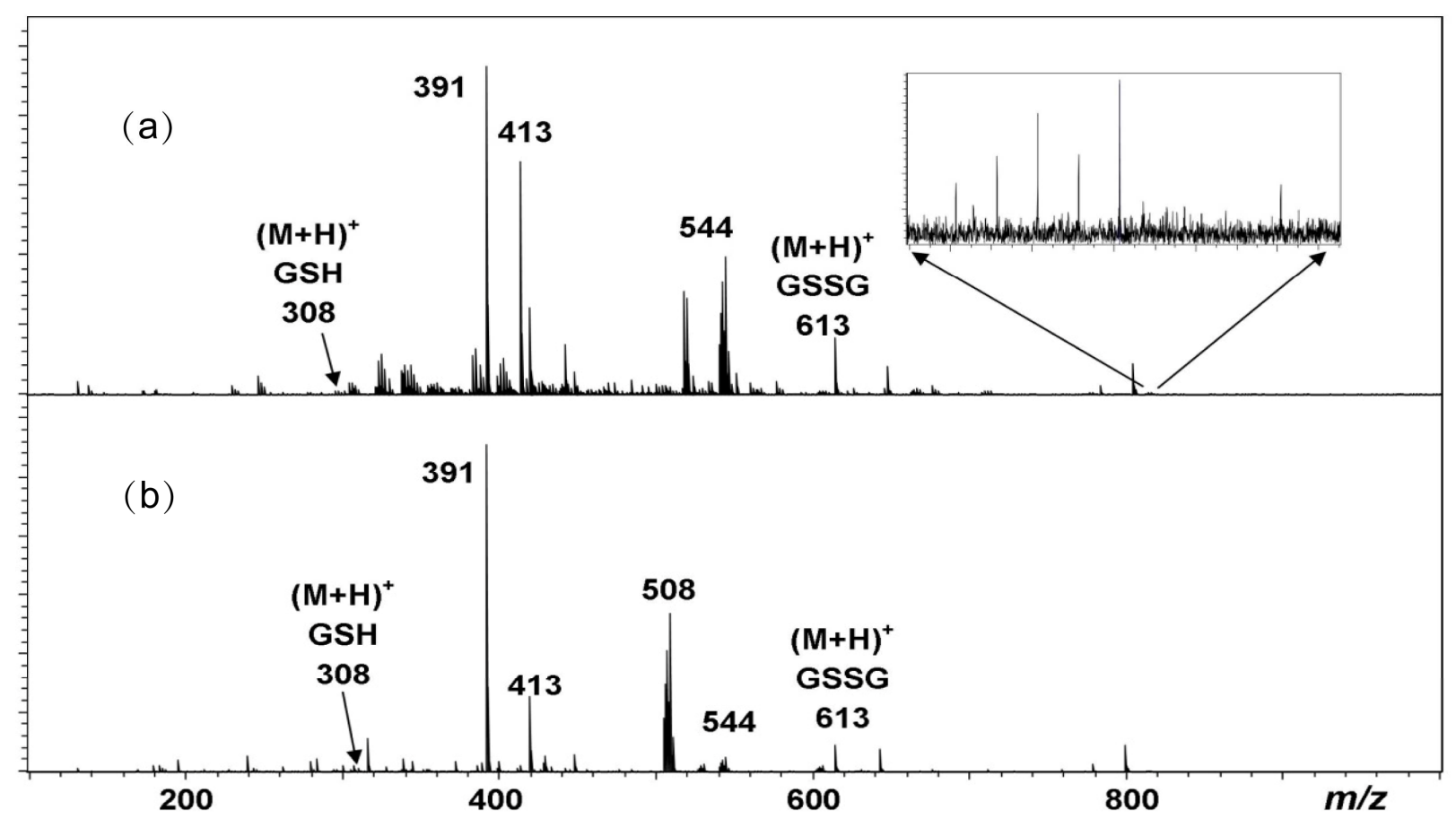

Figure 1. ESI-FTICR mass spectra of aqueous solutions of $\mathrm{Hg}(\mathrm{II})$ mixed with GSH (a) immediately after mixing $(\mathrm{t}=0)$ and $(\mathrm{b})$ after 4 days incubation at room temperature. The inset in Figure 1(a) represents the magnified region of $\mathrm{m} / \mathrm{z} 810-820$, indicating the presence $\left[(\mathrm{GS})_{2} \mathrm{Hg}+\mathrm{H}^{+}\right]$, which is confirmed by accurate mass analysis.

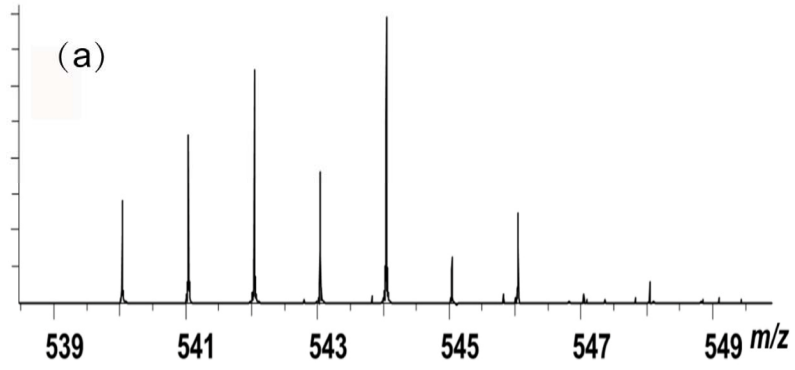

(b)

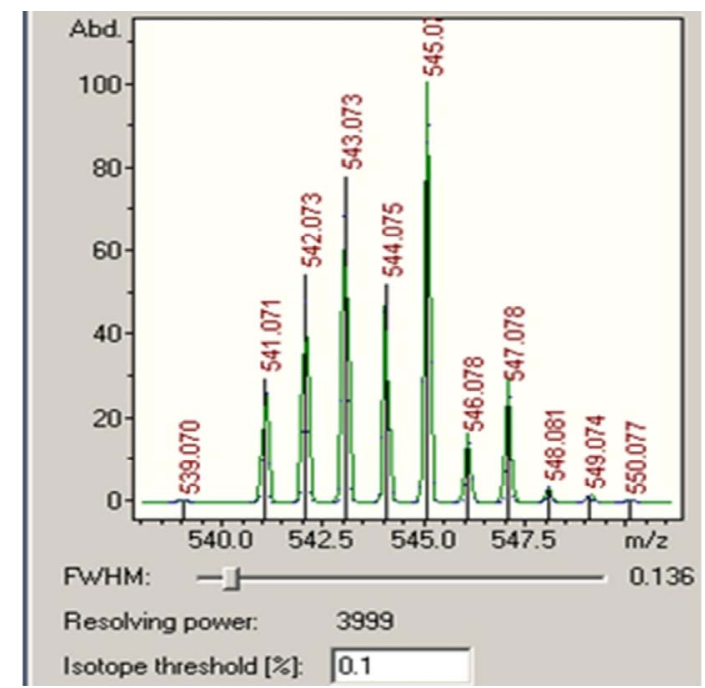

(c)

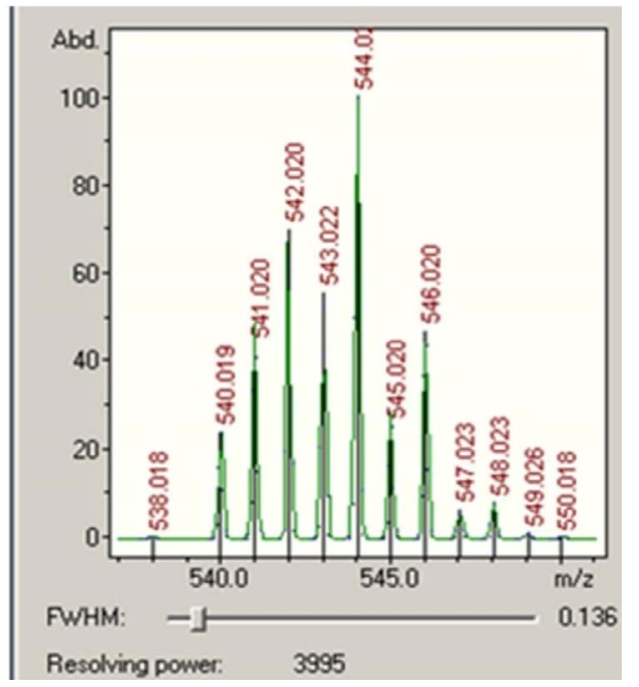

Figure 2. (a) Inset of ESI-FTICR mass spectrum of aqueous solutions of $\mathrm{Hg}(\mathrm{II})$ mixed with GSH after four days incubation at room temperature around $\mathrm{m} / \mathrm{z} 544$; (b) Simulated isotope distribution for $\left[\mathrm{Hg}(\mathrm{GSH})-\mathrm{H}+2 \mathrm{H}_{2} \mathrm{O}\right]^{+}$; (c) Simulated isotope distribution of $[\mathrm{GSH}+\mathrm{HgCl}]^{+}$. 
agreement with another possible formula corresponding to $[\mathrm{GSH}+\mathrm{HgCl}]^{+}$; a simulation of its theoretical isotope distribution is shown in Figure 2(c). The experimental ESI-FTICR data in Figure 2(a) agrees well not only with the theoretical isotopic distribution, but also with the predicted ionic mass $(544.0217 \mathrm{Da})$ with only $4.6 \mathrm{mDa}$ error.

To validate that chlorine was indeed present in this species, we conducted MS/MS using CID. The entire isotopic cluster centered about $\mathrm{m} / \mathrm{z} 544$ was mass-selected in the source quadrupole of the SolariX FT-ICR and dissociated with argon gas in the collision cell before transport to the FT-ICR ion trap. CID experiments were conducted over the range $8-16 \mathrm{~V}$, but the product ions generated only showed small differences in relative abundance and not in the actual product ions produced, so only the $12 \mathrm{~V}$ CID result is shown in Figure 3. CID confirms that chlorine is present in the formula for $\mathrm{m} / \mathrm{z}$ 544 ; neutral loss of $35.9764 \mathrm{Da}$ is observed, corresponding to loss of $\mathrm{HCl}$. The neutral loss of $111.0079 \mathrm{Da}$ is due to the loss of glycine hydrochloride from the C-terminus of GSH, which is followed by subsequent neutral losses of $\mathrm{H}_{2} \mathrm{O}$ and $\mathrm{NH}_{3}$, respectively. The peak at $\mathrm{m} / z$ $379.0032 \mathrm{Da}$ is consistent with the loss of the N-terminal $\mu$-glutamic acid residue $[17,18]$ from the $m / z 508$ product ion, while $m / z 306.0756$ corresponds to $\mathrm{GS}^{+}$; these results completely support a previously reported dissociation mechanism of the $1: 1 \mathrm{Hg}(\mathrm{II}): \mathrm{GSH}$ conjugate [9].

It is curious to consider how an aqueous solution of mercuric nitrate would produce this intriguing intermediate species. It should be noted that commercial mercuric nitrate does contain low levels of chloride impurities. Thus, GSH may form the intermediate by the following reaction:

$$
\mathrm{GSH}+\mathrm{HgCl}_{2} \rightarrow[\mathrm{GSH}+\mathrm{HgCl}]^{+}+\mathrm{Cl}^{-}
$$

In order to have such a composition with $\mathrm{Hg}$ (II) bound at the thiol, to maintain the overall mass of GSH, the Nterminus must be in its protonated form. If so, then the neutral loss of $\mathrm{HCl}$ can be explained as shown in Scheme 1. The product ion would then match the zwitterionic structure proposed for $m / z 508$ [9]. Additional support for this interpretation is derived from the fragmentation observed by CID, where the loss of the N-terminal and C-terminal amino acids from the conjugate occurs without the loss of the mercury atom, implying that it is indeed covalently bound to the central Cys residue.

\section{Conclusion}

Previous low-resolution ESI-MS of $\mathrm{Hg}$ (II) conjugates with GSH was unable to establish conclusively the identity of an isotopic cluster centered about $\mathrm{m} / \mathrm{z} 544$, although it was postulated that such an ion might be a 1:1 conjugate with two associated water molecules. Here, the

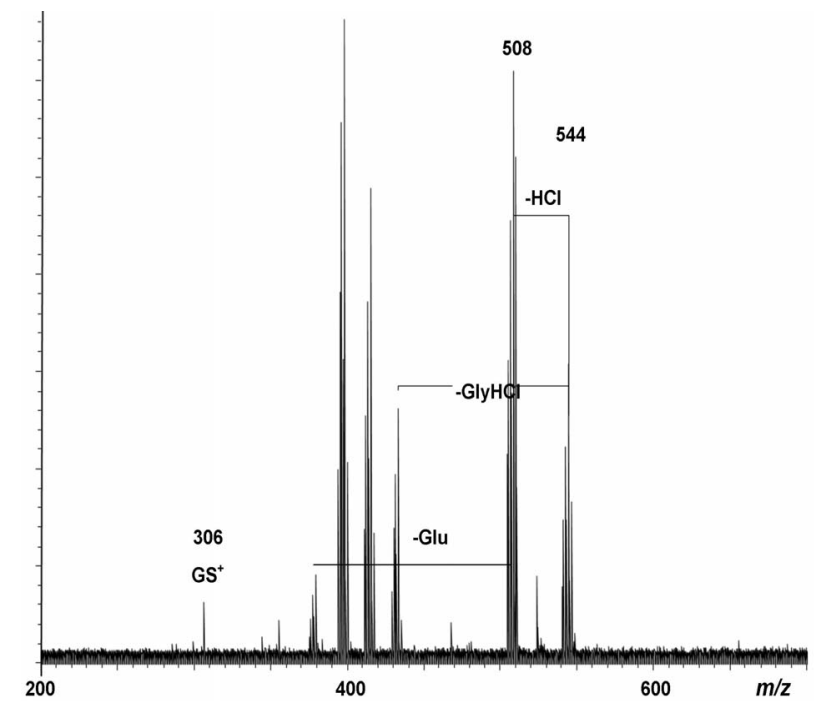

Figure 3. CID(12V) of the $m / z 544$ cluster generated by ESIFTICR.

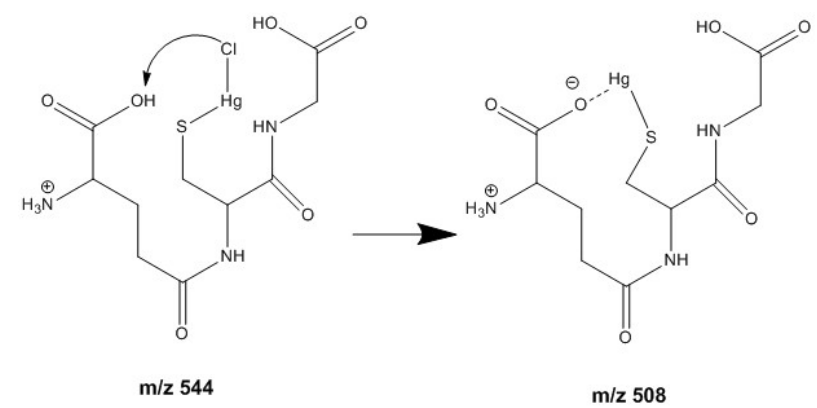

Scheme 1. Fragmentation of $\left[\mathrm{GSH}+\mathrm{HgCl}^{+}\right.$intermediate.

high mass accuracy capability of FT-ICR coupled to an ESI source of $\mathrm{Hg}(\mathrm{II})-\mathrm{GSH}$ mixtures establishes that the isotopic cluster is $\left[\mathrm{GSH}+\mathrm{HgCl}^{+}\right.$; further confirmation is established through the observed isotopic ratios, consistent with a species containing single $\mathrm{Hg}$ and $\mathrm{Cl}$ atoms, and CID, which shows neutral loss of $\mathrm{HCl}$ upon collisional activation of the precursor ion. Based on kinetics studies, the conjugate apparently forms immediately upon mixing. However, the conjugate species [GSH + $\mathrm{HgCl}]^{+}$observed is unstable, and eventually decays into $[\mathrm{GSH}-\mathrm{H}+\mathrm{Hg}]^{+}$, an isotopic cluster centered about $\mathrm{m} / \mathrm{z}$ 508, which has been reported previously. Thus, the high mass accuracy capability of FT-ICR provides insight into the mechanism of formation of a prominent organomercury thiol.

\section{Acknowledgements}

The authors would like to thank Heather Rudolph, Will Friesen, Charmion Cruickshank, and Kevin Quinn for helpful discussions. Acquisition of the FT-ICR mass spectrometer was supported by the National Institutes of Health (S10-RR029517). 


\section{REFERENCES}

[1] M. Valko, D. Leibfritz, J. Moncol, M. T. Cronin, M. Mazur and J. Telser, "Free Radicals and Antioxidants in Normal Physiological Functions and Human Disease," International Journal of Biochemistry \& Cell Biology, Vol. 39, No. 1, 2007, pp. 44-84. http://dx.doi.org/10.1016/j.biocel.2006.07.001

[2] H. Xu and M. Hepel, "Molecular Beacon-Based Fluorescent Assay for Selective Detection of Glutathione and Cysteine," Analytical Chemistry, Vol. 83, No. 3, 2011, pp. 813-819. http://dx.doi.org/10.1021/ac102850y

[3] M. Valko, H. Morris and M. T. Cronin, "Metals, Toxicity and Oxidative Stress," Current Medicinal Chemistry, Vol. 12, No. 10, 2005, pp. 1161-1208. http://dx.doi.org/10.2174/0929867053764635

[4] W. Stricks and I. M. Koltoff, "Reactions between Mercuric Mercury and Cysteine and Glutathione. Apparent Dissociation Constants, Heats and Entropies of Formation of Various Forms of Mercuric Mercapto-Cysteine and -Glutathione," Journal of the American Chemical Society, Vol. 75, No. 22, 1953, pp. 5673-5681. http://dx.doi.org/10.1021/ja01118a060

[5] B. J. Fuhr and D. L. Rabenstein, "Nuclear Magnetic Resonance Studies of the Solution Chemistry of Metal Complexes. IX. The Binding of Cadmium, Zinc, Lead, and Mercury by Glutathione," Journal of the American Chemical Society, Vol. 95, No. 21, 1973, pp. 6944-6950. http://dx.doi.org/10.1021/ja00802a013

[6] R. K. Zalups, "Molecular Interactions with Mercury in the Kidney," Pharmacological Reviews, Vol. 52, 2000, pp. 113-143.

[7] V. Mah and F. Jalilehvand, "Glutathione Complex Formation with Mercury(II) in Aqueous Solution at Physiological pH," Chemical Research in Toxicology, Vol. 23 , No. 11, 2010, pp. 1815-1823. http://dx.doi.org/10.1021/tx100260e

[8] E. M. Krupp, B. F. Milne, A. Mestrot, A. A. Meharg and J. Feldmann, "Investigation into Mercury Bound to Biothiols: Structural Identification Using ESI-Ion-Trap MS and Introduction of a Method for Their HPLC Separation with Simultaneous Detection by ICP-MS and ESI-MS," Analytical and Bioanalytical Chemistry, Vol. 390, No. 7, 2008, pp. 1753-1764. http://dx.doi.org/10.1007/s00216-008-1927-x

[9] F. M. Rubino, M. Pitton, G. Brambilla and A. Colombi, "A Study of the Glutathione Metaboloma Peptides by Energy-Resolved Mass Spectrometry as a Tool to Investigate into the Interference of Toxic Heavy Metals with Their Metabolic Processes," Journal of Mass Spectrome- try, Vol. 41, No. 12, 2006, pp. 1578-1593. http://dx.doi.org/10.1002/jms.1143

[10] N. Burford, M. D. Eelman and K. Groom, "Identification of Complexes Containing Glutathione with As(III), $\mathrm{Sb}(\mathrm{III}), \mathrm{Cd}(\mathrm{II}), \mathrm{Hg}(\mathrm{II}), \mathrm{Tl}(\mathrm{I}), \mathrm{Pb}$ (II) or $\mathrm{Bi}(\mathrm{III})$ by Electrospray Ionization Mass Spectrometry," Journal of Inorganic Biochemistry, Vol. 99, No. 10, 2005, pp. 1992 1997. http://dx.doi.org/10.1016/j.jinorgbio.2005.06.019

[11] F. M. Rubino, C. Verduci, R. Giampiccolo, S. Pulvirenti, G. Brambilla and A. Colombi, "Molecular Characterization of Homo- and Heterodimeric Mercury(II)-BisThiolates of Some Biologically Relevant Thiols by Electrospray Ionization and Triple Quadrupole Tandem Mass Spectrometry," Journal of the American Society for Mass Spectrometry, Vol. 15, No. 3, 2004, pp. 288-300. http://dx.doi.org/10.1016/j.jasms.2003.10.013

[12] S. J. James, P. Cutler, S. Melnyk, S. Jernigan, L. Janak, D. W. Gaylor and J. A. Neubrander, "Metabolic Biomarkers of Increased Oxidative Stress and Impaired Methylation Capacity in Children with Autism," American Journal of Clinical Nutrition, Vol. 80, No. 6, 2004, pp. 1611-1617.

[13] J. Mutter, J. Naumann, R. Schneider, H. Wallach and B. Haley, "Mercury and Autism: Accelerating Evidence?" Neuro Endocrinology Letters, Vol. 26, 2005, pp. 439-446.

[14] T. W. Clarkson and L. Magos, "The Toxicology of Mercury and Its Chemical Compounds," Critical Reviews in Toxicology, Vol. 36, No. 8, 2006, pp. 609-662. http://dx.doi.org/10.1080/10408440600845619

[15] P. Caravatti and M. Allemann, "The Infinity Cell-A New Trapped Ion Cell with Radiofrequency Covered Trapping Electrodes for Fourier Transform Ion Cyclotron Resonance Mass Spectrometry," Organic Mass Spectrometry, Vol. 26, No. 5, 1991, pp. 514-518. http://dx.doi.org/10.1002/oms.1210260527

[16] A. G. Marshall, C. L. Hendrickson and G. S. Jackson, "Fourier Transform Ion Cyclotron Resonance Mass Spectrometry: A Primer," Mass Spectrometry Reviews, Vol. 17, No. 1, 1998, pp. 1-35. http://dx.doi.org/10.1002/(SICI)1098-2787(1998)17:1<1:: AID-MAS1>3.0.CO;2-K

[17] A. G. Harrison, "Ion Chemistry of Protonated Glutamic Acid Derivatives," International Journal of Mass Spectrometry, Vol. 210, 2001, pp. 361-370. http://dx.doi.org/10.1016/S1387-3806(01)00405-5

[18] A. G. Harrison, "Fragmentation Reactions of Protonated Peptides Containing Glutamine or Glutamic Acid," Journal of Mass Spectrometry, Vol. 38, No. 2, 2003, pp. 136-144. http://dx.doi.org/10.1002/jms.427 